\title{
Wikis in school libraries
}

\author{
Dana Dukic \\ Librarian \\ Kowloon Junior School \\ Hong Kong
}

The Web 2.0 thinking and accompanying technologies opened a new direction of development for libraries. Among different Web 2.0 applications wikis are particularly attractive for school librarians. Wikis are read-write web pages that are easy to use, accommodate other Web 2.0 features and are widely applicable for a number of purposes. A Wiki space named LibraryZone is a good example of using wiki in elementary school library. LibraryZone is used for information literacy instructions, conducting a collaborative project, for story writing and as a discussion space.

In her video interview with Reading Rockets, Jane Yolen, a famous children's author, said the following about creative writing in school:

I think that there are two problems with the way writing is done in schools. One is the assumption that you can give an assignment, and anyone can then blurt out onto the page enough in a 20-minute period, or a 15-minute period, or half hour - whatever the period us. I can't do that. So, you give kids a topic, and you give them a time. And within that topic and that time, you're saying, 'Do something creative'. For most kids, that's enough to stop them right there.

I would rather have kids have journals that they can take home and write on when they feel like it.

According to Jane Yolen, creative writing is an activity that can't be strictly slotted in a school timetable. Children and adults alike can write when they come up with some interesting ideas, when they feel like writing and for school children, this doesn't always happen during their school lessons.

With new Web 2.0 technologies there is no need for children to carry around journals or anything similar. There are a number of Web 2.0 applications that teachers can use to set up a creative writing project for their students online and enable students to work on the assignment at any time and place they like. All they need is a computer with the Internet access.

According to the new trends in educational theory the concept of education is defined in a much broader sense. It operates across different domains: school, home and wider community. The concept of learning has also changed. Learning is not only acquiring new knowledge but also developing students' attitudes and skills that will keep them open to new learning experience beyond the boundaries of school and formal education. 
In addition, learning is more personalized, adjusted to students' individual interests and potentials, and involves collaboration across time and space. The concept of Web 2.0 as an open and interactive interface meets perfectly the new needs of educators and students. The new read and write web enables teachers to create and deliver interactive learning materials online that their students can access at their convenience.

\section{Web 2.0 and libraries}

Web 2.0 thinking and the accompanying technologies (O'Reilly, 2005) opened a new direction of development for libraries. A number of libraries are already moving in the direction of Web 2.0, under the name of Library 2.0, a term that Michael Casey (2006) introduced in his LibraryCrunch blog.

School Library 2.0 is a direct sequel of Library 2.0. It harnesses Web 2.0 applications, mixing them and remixing so as to create library services and collections that can meet personalized needs of its end-users. Indeed, school library 2.0 is a mash up (Wikipedia, 2006). It combines traditional library services with innovative Web 2.0 services. It is a hybrid of blogs, wikis, streaming media, podcasts, content aggregators, instant messaging and social networks.

School library 2.0 is a physical and virtual space, accessible to its users at any time and from any location. It is completely user-centered and users-driven. Librarians 2.0 are not any more primarily responsible for the creation of the content. They act as facilitators of different services. Library users create library resources and services in collaboration with one another and with librarians. School library 2.0 is a perpetual beta, being always in a testing phase, developing and releasing services with constant updates.

School library 2.0 revolutionizes the library profession. Rather than creating systems and services for patrons, librarians enable users to create them for themselves.

Among different Web 2.0 applications wikis are particularly attractive for school librarians. Wikis are easy to use, flexible in managing and widely applicable. Furthermore, wikis are increasingly developing capabilities to incorporate other Web 2.0 applications.

\section{What are Wikis and how do they work?}

Wiki, meaning quick in Hawaiian, is an easy and effective online collaboration tool. Wikis are simple websites that are created and edited by many authors. The main advantage of wikis is that users can always add new information and edit previous authors' submissions. Wikis allow their users to compare previous versions of its pages and also to track who wrote or edited what and when. All wikis are browser-based applications, available to end-users any time and at any location. All they need to access wiki is a computer with the internet connection.

Wikis mainly offer 3 types of web space: public space that can be viewed and edited by anyone, protected space that can be viewed by anyone but can only be edited by members of the 
space and private space that can only be viewed or edited by members of the space. Well known example of public wiki is Wikipedia (2006), a collaborative online encyclopedia. There are a number of wiki tools available on the Internet: PB Wiki, JotSpot, WetPaint, PMWiki, MediaWiki, Ning, Mike and WikiSpaces.

\section{Wikis in school libraries}

Wikis are used in school libraries in many different ways. They are used for creating library and information skills tutorials (Library Instruction Wiki, 2007), conducting collaborative educational projects (Grandview Library, 2007; Moncrief Library Wiki, 2007), creating various reading lists (Pyplibrary, 2007; ATN Reading Lists, 2007), writing book reviews (LMC reviews, 2007; Tiger Talk, 2007; Childrenbooksreviews, 2007), building a database of professional resources (Library Success: a Best Practices Wiki, 2007; LISWiki, 2007; Teacherlibrarianwiki, 2007; TeacherLibrarianNing, 2007; Librarianedge 2007) or can be used just as a webpage for professional associations (ALA-APA Union Wiki, 2007; SLIC, 2007; ALESS, 2007).

\section{LibraryZone}

LibraryZone (2007) is a wiki space established as a supplement to a school library website. Students can access LibraryZone directly from the school library homepage. Even though a school library website is browser-based and interactive itself, currently it doesn't provide some features and services available in wikis.

LibraryZone is built with software named Wikispaces. Wikispaces is very convenient for educational purposes. It is easy to use, offers the possibility that only invited members can edit the content, and a no-ads version is freely available to educators working in K-12 schools.

In Wikispaces there is a built-in visual editor that lets users see the layout and design of the page while editing it. It contains a visual history page, an auto-save option to save drafts during editing process, and a searching and tagging function.

Wikispaces has a capability to upload various files (text, pictures, audio, and video) or to embed various media (audio, video, multimedia). It contains a discussion forum that allows users to input comments or send emails as well as an option to import a blog. Very useful features of Wikispaces are usage statistics and page feeds with email notification of changes to any space or page with RSS feeds. Last but not least Wikispaces is supported by a good customer service and it is very easy to make wiki space backups at any time.

Wikispaces software is in the process of testing, and it constantly adds new features and components. Users can even subscribe to receive regular updates.

LibraryZone makes use of most features available through Wikispaces. It is a protected space so that everybody can see it but only members can edit it. Members in LibraryZone are Year 3 students from the school library club, and the librarian. LibraryZone operates as a 
collaborative learning platform for students. It is a mash up of different applications and services. In LibraryZone students learn research skills, work on collaborative research projects, generate information resources, write stories, communicate with one another and with the librarian and initiate discussions about different issues. They use the wiki as a text editor and as a web space where they can import many different files and applications.

\section{LibraryZone Services}

\section{Information literacy instruction}

Web 2.0 technologies introduce changes in delivering library instruction and enhance the information literacy of library users. A lot of school libraries already offer online tutorials containing flash programming, streaming audio and video, combined with interactive quizzes and handouts for downloading (OSLIS, 2007; KYVL, 2007). Web-based tutorials are very convenient because they are available any time and at any geographical location. Students can access the tutorial when they need it and can study at their own pace. A drawback of online tutorials is that students have no opportunity to interact with the instructor or with other students. This shortcoming of web-based tutorials can be solved by introducing a wiki as a platform for creating library instruction tools. Tutorials set as a wiki space allow users to put their comments on any part of the tutorial, to suggest improvements or even inclusion of some new contents. Wiki based tutorial is permanently in a testing phase, constantly being improved and extended by its users. This feature is particularly important for developing teaching tools in the area of information literacy where changes are so dynamic and radical.

The idea underpinning the whole Web 2.0 concept is that large groups of diverse people are smarter than a few experts (Surowiecki, 2004) and it has huge implications for developing various teaching tools. The more people work on them the better they are.

An interesting example of using wiki to collaboratively develop information literacy teaching tools is Library Instruction Wiki (2007), started by librarians working in university libraries in the USA.

LibraryZone wiki was initially set up as a research skills tutorial. The tutorial was created with intention to push library instructions online and its targeted audience is year 3 students. It covers main aspects of the research procedure, like planning the entire research, choosing resources, searching the internet, website evaluation, taking notes and creating a presentation.

The Research skills tutorial is a combination of text, pictures, animations, movies and audios. It contains interactive quizzes, short PP lessons, exercises and worksheets. The work on the tutorial is an ongoing process. It is liable to changes based on users' suggestions and new technology development.

\section{Collaborative creating library resources}

Building up school library collections has always been considered a collaborative process. Alongside resources like publishers' catalogs, books reviews, advertisements, etc. the 
contribution from library users, teachers and students is extremely important for developing a well resourced school library.

It was always a part of librarian's responsibility to encourage teachers and students to make requests for specific resources. But in busy schools it is not always easy to maintain regular input from school library users. Setting up a library wiki opens a space for librarians, teachers and students to meet each other, to talk about their information needs, to suggest new library services and do it at the time that is most convenient for them.

Here are examples of creating library information resources in collaboration with students. As the part of the Weather project students generated a list of fiction and nonfiction books about weather from the Library collection. Although the work on these lists was a part of their library and information researching skills lesson students produced useful library resource that was used by P3 teachers for their unit of inquiry about weather.

Another learning task for students on the Weather project was to evaluate a list of websites about weather. Students were given a questionnaire about the website quality according the usual criteria like the presence of the website author, last update, quality of links and uploads, domain name etc. The results of students' evaluations are put on the webpage as a guide for future users.

In the project named Lucky Ladybugs students generated a list of websites about ladybugs suitable for elementary school children. They also set up a quiz for testing knowledge about ladybugs. The quiz is created in a program called Hot Potatoes.

\section{Conducing a collaborative project}

Wikis are ideal for conducting a collaborative project. In collaborative projects students plan their work together, decide about different jobs, check and discuss each other's work, and construct new knowledge. Wiki page enables students to work at school and from home, and they can access project pages any time they like. They can always find out who wrote what and when, discuss their work online and send messages.

A research project The Solar System is an example of a collaborative project. The project was based on the story Postcards from Pluto: A Tour of the Solar System written by Loreen Leedy.

This project was primarily an exercise in taking notes. Students were organized in teams of 2 or 3, and given a worksheet with questions to scaffold their learning. Each group was in charge of one planet or the sun or the moon. Websites about the solar system appropriate to their age were located on the Resource page. Student explored the websites, searched for interesting information about their planet and wrote down their notes on the Note page. During the process of taking notes students were encouraged to look over each other's work and add up more information. In the end the practice of searching for information about the solar system and taking notes turned into a genuine collaborative activity. Working together students generated notes containing a lot of information about the solar system that they could use to create their presentations. 
Note taking is the most difficult and most important part of the research skills. During the process of taking notes students construct the meaning from the text and acquire new knowledge and skills. By taking notes collaboratively students facilitate each other's learning and by bringing in their different interests and skills enhance the whole group's performance.

\section{Story writing}

As Jane Yolen says, students should be given an opportunity to write when they feel like it. Wiki as an open software is a perfect story writing tool. Students can access the wiki page and write stories from their classroom, from the Library, from the ICT room, from home or from any other place where they have the internet access.

In LibraryZone wiki there are pages reserved for students' stories. These pages were created on students' demand. Students showed great interest in writing stories connected to the themes of their research projects. They wrote stories about thunderstorms, about ladybugs and about space. A short look into the history of story pages shows that students took the advantage of wiki being always accessible. They sometimes worked on their stories at school and sometimes from home. At school they mostly wrote during the library club, but at times they wrote during school lunch break and occasionally in the classroom.

Through the LibraryZone wiki students were not only given a freedom to choose when and where to write their stories but also offered an opportunity to publish their work and show it to colleagues, friends and family.

\section{Discussion space}

Discussion page in Wikispaces is an open forum for wiki members. They can to put their comments about the contents on the wiki, discuss any topic of their interest, ask questions, offer some tips, give suggestions for further work or just pass some information to others. In the beginning of the LibraryZone project students used only email. At times they used it for the project related goals and every so often for some private purposes. After some time, when they became more confident with the wikispaces software, they started using discussion pages. They used discussion pages to inform wiki members about their new edits, to pass some interesting things they learned recently or to comment the page contents. Discussion page in wiki is for young students a big challenge to publicly express their opinion about the work of their colleagues or teachers.

\section{Web 2.0 applications in LibraryZone}

In LibraryZone wiki space is not used only as a read and write web. It is used as a platform for mashing up all kinds of applications. Wikispaces is software that already has a builtin ability to import different types of files and to embed various applications in audio, video or multimedia formats. By making use of this powerful feature of Wikispaces LibraryZone is turned to a multimedia reach interactive web space. 
As a part of the Weather project students together with librarian created a podcast about thunderstorms. The podcast is published through application called ClickCaster and is embedded on the Thunder Cake page. On the same page there are also a number of audio clips with students talking about the story The Thunder Cake by P. Polacco. These audios are recorded with Audacity free software, uploaded to the wiki page in MP3 format and inserted to the page.

In Exploring space project there is a page that contains different information resources about space. Among various resources included there are a number of movies about planets in solar system. Some movies are uploaded on the Wikispaces and inserted into the page and some are embedded from the web-based application called TeacherTube.

HotPotato is another application suitable for school projects that can be easily inserted into Wikispaces. A student working on the project named Lucky Ladybugs used HotPotato software to create a quiz about ladybugs. Some other students working on the same project presented their work in PhotoStory. Both works were uploaded to the wiki space and inserted into the project page.

In Research skills tutorial the content of wiki is enhanced by importing teaching resources created in PowerPoint, HotPotato, Flash, and by inserting many other types of text, graphic, audio and video files.

\section{Conclusion}

Web 2.0 technologies radically changed the role of the school library. From the 'room of books' the school library turns into a central hub of information processing. Through Web 2.0 tools librarians can access a remarkable number of resources in many different formats and build collections and services that can meet different learning needs.

Among the new read-write web tools wikis have became very popular with school librarians. Wikis are very convenient because they are always accessible and allow their users to keep a track of all new edits. Librarians use wikis to build tutorials, to collaborate with users in generating library resource, and to conduct all kinds of activities.

Wikis are also so user friendly that even primary school students can use them without difficulty. The LibraryZone shows that, indeed, wiki space can be successfully used for work even with 7 years old children. For these young students LibraryZone was a space they used to present their work and to communicate with one another and with librarian. Wikis are also safe environment for young students because their access can be controlled.

Wikis are not only text editors, they have a capability to incorporate other Web 2.0 applications like blogs, podcasts, streaming media, RSS feeds, asynchronous messaging, discussion forums, tags and so forth. Wikis function as computing platforms that can successfully satisfy different needs of school libraries. 


\section{References:}

ALA-APA Union Wiki. Retrieved March 18, 2007, from http://alaapaunion.pbwiki.com/School+Library+Union+News

ALESS. Retrieved March 18, 2007, from http://aless.wikispaces.com/

ATN Reading Lists. Retrieved March 18, 2007, from http://atn-reading-lists.wikispaces.com/

Casey, M. (2006). Born in the biblioblogosphere. LibraryCrunch, January 3, 2006. Retrieved October 18, 2006, from http://www.librarycrunch.com/2006/01/post_1.html

Childrenbooksreviews. Retrieved March 18, 2007, from http://childrensbookreviews.pbwiki.com/

ClickCaster. Retrieved January 18, 2007, from http://www.clickcaster.com/

Grandview Library. Retrieved March 18, 2007, from http://www.grandviewlibrary.org/ThirdGradeWikis.aspx

Harris C.G. (2006) SL2.0: Capturing Web 2.0. Informancy, January 9, 2006.

KSMA. Retrieved January 18, 2007, from http://kysma.pbwiki.com/FrontPage

KYVL. Retrieved January 12, 2007, from http://www.kyvl.org/html/kids/homebase.html

Leedy, L. (1996). Postcards from Pluto: A Tour of the Solar System. New York: Holiday House.

Librarianedge. Retrieved March 19, 2007, from http://librarianedge.pbwiki.com/

Library Instruction Wiki. Retrieved February 10, 2007, from http://instructionwiki.org/Main_Page

Library Success: a Best Practices Wiki. Retrieved January 15, 2007, from http://www.libsuccess.org/index.php?title=Main_Page

LibraryZone. Retrieved March 15, 2007 from https://libraryzone.wikispaces.com/

LISWiki. Retrieved January 12, 2007, from http://liswiki.org/wiki/LISWiki:About

LMC Reviews. Retrieved March 11, 2007, from http://www.seedwiki.com/wiki/lmc_reviews/

Manes, J. M. (2006). Library 2.0 Theory: Web 2.0 and its implications for Libraries. Webology, 3(2), Article 25. Available at: http://www.webology.ir/2006/v3n2/a25.html

Mashups (web application hybrids). (2006). Wikipedia article. Accessed January 10, 2007, from http://en.wikipedia.org/wiki/Mashup_(web_application_hybrid)

McPherson, K. (2006). Wikis and literacy development. Teacher Librarian, 34(1), 67-69.

Miller, P. (2005). Do libraries matter?: The rise of library 2.0 (A Talis White Paper), Talis. Retrieved March 18, 2007, from http://www.talis.com/downloads/white_papers/DoLibrariesMatter.pdf

Moncrief Library Wiki. Retrieved March 18, 2007, from http://moncrieflibrary.pbwiki.com/

Oatman, E. (2005). Make way for wikis. School Library Journal, 51(11), 52-54.

O'Reilly, T. (2005). What is web 2.0? Retrieved May 18, 2006, from http://www.oreillynet.com/pub/a/oreilly/tim/news/2005/09/30/what-is-web-20.html\#mememap 
OSLIS. Retrieved January 12, 2007, from http://www.oslis.org/elementary/index.php

PYPlibrary. Retrieved March 26, 2007, from http://pyplibrary.wikispaces.com/

Reading Rockets. Retrieved March 1, 2007, from http://www.readingrockets.org/books/interviews/yolen

SLIC. Retrieved January 8, 2007, from_ http://slic.wikispaces.com/

Surowiecki, J. (2004). The Wisdom of Crowds. London: Abacus

TeacherLibrarianNing. Retrieved March 18, 2007, from http://teacherlibrarian.ning.com/

Teacherlibrarianwiki. Retrieved March 2, 2007, from http://teacherlibrarianwiki.pbwiki.com/

Tiger Talk. Retrieved January 5, 2007, from: http://tigertalk.wikispaces.com/

Wikipedia. Retrieved November 8, 2006, from www.wikipedia.com

\section{Biographical Notes}

Dana Dukic holds a Ph. D. in library and information science, and has worked in university and medical libraries in Croatia and UK. She was also involved in teaching undergraduate and graduate courses in the area of LIS at the University of Zagreb. At present she works at the Kowloon Junior School in Hong Kong. Her interests are teaching information literacy in Web 2.0 environment, information management, and sociology of the Web. 